\title{
Abundance And Characteristics of Microplastics Contaminating The Surface Water of The Inner Gulf of Thailand
}

\section{Pathompong Vibhatabandhu}

Chulalongkorn University

Sarawut Srithongouthai ( $\square$ sarawut.sr@chula.ac.th )

Chulalongkorn University https://orcid.org/0000-0002-2074-2680

\section{Research Article}

Keywords: microplastic, surface water, Inner Gulf of Thailand

Posted Date: May 11th, 2021

DOl: https://doi.org/10.21203/rs.3.rs-400647/v1

License: (c) (1) This work is licensed under a Creative Commons Attribution 4.0 International License.

Read Full License

Version of Record: A version of this preprint was published at Water, Air, \& Soil Pollution on February 1 st, 2022. See the published version at https://doi.org/10.1007/s11270-022-05531-x. 


\section{Abstract}

Microplastics are pollutants with uncertain behaviors; they have mysterious impacts on marine environments. In the present study, surface water samples from 25 different locations in the Inner Gulf of Thailand were collected to assess the distribution of microplastic contamination. Microplastics were visually counted and identified by Fourier-transform infrared microscopy. The results revealed that the average total abundance of microplastics $(125-5000 \mu \mathrm{m})$ was 9.97 pieces/L $(1.55 \mathrm{ng} / \mathrm{L})$. Microplastics sized $125-300 \mu \mathrm{m}$ were most abundant at all the sampling sites, accounting for $68 \%$ of the total microplastics. Fiber (35\%) and fragment (34\%) were the predominant microplastic shapes in the surface water. Polyethylene, polypropylene, and poly(ethylene propylene) accounted for the most prevalent polymer types. The present findings revealed that the Inner Gulf of Thailand is moderately polluted by microplastics of different sizes, shapes, and types, which may pose a potential risk to coastal ecosystems.

\section{Introduction}

Plastic is a dynamic material that has widespread applications; however, it poses a significant threat to marine ecosystems. It is estimated that between 4.8 and 12.7 million tons of plastic debris entered the oceans in 2010 and that this number may increase to 100-250 million tons by 2025 (Jambeck et al. 2015). Consequently, marine plastic debris is considered an alien solid interacting with natural environmental components. The term microplastic (MP) debris refers to plastic particles (also known as plasticles) smaller than $5 \mathrm{~mm}$ that are manufactured (primary MPs) and small pieces that emerge from the fragmentation of large plastic debris (secondary MPs) (Cole et al. 2011). The behavior of MPs has been continuously studied to determine where and how they affect the environment.

After being released into a dynamic aquatic environment, MPs are transported and transformed by physical, chemical, and biological processes. River discharge, wind, waves, and surface currents are the main factors inducing the horizontal transport of MPs, which mostly float on surface water (Zhang 2017). Plastics are activated by ultraviolent radiation, temperature, and weathering processes in the environment and become yellow and fragmented as a result of photooxidative reactions, thermal reactions, and mechanical forces (e.g., wave action, abrasion with sand, or contact with animals) (Andrady 2011, Andrady 2017). MPs not only float on surface water but also sink to the water column and accumulate in sediments. Plastics generally settle when they are denser than seawater, e.g., polyvinylchloride (PVC) $\left(1.16-1.58 \mathrm{~g} / \mathrm{cm}^{3}\right)$. On the other hand, lighter plastics are subject to biofouling; natural compounds accumulating on the plastic surface can increase their density and sedimentation on the seabed (Zhang 2017, Hidalgo-Ruz et al. 2012, Chubarenko et al. 2016, Wang et al. 2016). With environmental movement and aggregation processes, MPs can be transported to all components of the ecosystem while being degraded simultaneously.

The ecological impacts of the environmental transformation of MPs have been discussed in terms of the intrinsic toxicity of plastics and the pollutants that are adsorbed or released from MPs. The exposure of 
MPs to the environment increases oxidative stress and inhibits various metabolic pathways. Moreover, given their bioinert nature, ingested pseudo-food MPs can get accumulated in the gastrointestinal tract and result in reduced food consumption (Anbumani and Kakkar 2018). For instance, the photosynthesis, electron transportation rate, reaction center activity, and efficiency of the oxygen-evolving complex in the phytoplankton Chlorella pyrenoidosa were found to decrease after exposure to polystyrene in the culture media (Mao et al. 2018). As a result, electrons accumulated in the cell and oxygen species increased. The alga was thus under oxidative stress, which stimulated lipid peroxidation and damaged the cell membrane. In addition, the toxicity of MPs can be viewed as a vector for accumulating and transferring toxic substances to the ecosystem. The high partition coefficient of MPs indicates their strong potential for the persistent adsorption of organic pollutants (Huffer et al. 2018, Rochman et al. 2013, Wang and Wang 2018). Furthermore, MPs can accumulate heavy metals (Ashton et al. 2010, Rochman et al. 2014, Munier and Bendell 2018, Wang et al. 2017). However, both toxic organic and heavy metal compounds may consist of additive chemicals used in plastic products (Hahladakis et al. 2018). The adsorption and desorption of toxic chemicals on plastics can be explained on a case-by-case basis in terms of how they affect the release of toxic biota or exclude toxic components from them (Koelmans et al. 2016). It is very important to assess the fate and transportation of MPs in order to obtain information about their effects on and behavior in the environment.

The impacts of MP contamination are of concern; it is estimated that 0.2-0.4 million metric tons of plastics entered the sea from Thailand in 2010 (Jambeck et al. 2015). The Inner Gulf of Thailand (Fig. 1) is a shallow, semi-enclosed bay located below the largest land area of the country. It is a valuable resource for economic and ecological services. Above the Inner Gulf of Thailand, the Mae Klong, Tha Chin, Chao Phraya, and Bang Pakong rivers transport fresh water along with pollutants from the mainland. The surface current thorough the Inner Gulf of Thailand is mainly regulated by monsoon winds and is possibly related to northward river water discharge. The current exhibits clockwise circulation during the southwest monsoon period (May-August) and some counterclockwise circulation during the northeast monsoon period (November-January) (Buranapratheprat 2008). In addition, recreational beaches and industrial areas are located on the western and eastern sides of the Inner Gulf of Thailand. As it is known that plastics are sourced from anthropogenic activities, it can be accepted that plastic waste from various sources surrounding the land enters this area. Importantly, the plastics could be fragmented to MPs by the physicochemical dynamic reactions of river and beach environments. These MPs may either accumulate in the gulf or get exported to the open sea.

However, little information has been published about MPs in the Inner Gulf of Thailand. As per reported data, sessile invertebrates in the eastern coast of the gulf accumulate MPs at a level of $0.2-0.6$ pieces $/ \mathrm{g}$ (Thushari et al. 2017). Moreover, MP contamination has been reported to increase significantly from sediments in the 6-12 cm layer (dating from the 1980s) to surface sediments (dating from the 2000s) (Matsuguma et al. 2017). The present study aimed to assess the abundance and characteristics of MPs contaminating the surface water of the Inner Gulf of Thailand. We assessed the concentrations, sizes, shapes, and types of MPs in the Inner Gulf of Thailand and compared them with those of MPs in other 
international waters. Our findings will provide background information for plastic waste management in the Inner Gulf of Thailand.

\section{Methodology}

\section{Sample collection}

Samples of MPs in water were collected from 25 locations in the Inner Gulf of Thailand (Figure 1) in December 2017. Suspended solids in 100-200 L of surface water (0-20 cm depth) were collected using a clean bucket and filtered through a $125 \mu \mathrm{m}$ phytoplankton net. The mixture of particles was transferred to new polypropylene (PP) bottles that were deeply cleaned using a surface-active cleaning agent and rinsed with distilled water. Before analysis, the samples were stored in cool and dark containers for preserving the microbial activities.

\section{Analysis of microplastics}

The MP analytical protocol was modified from Methods for the Analysis of Microplastics in Water Samples, the protocol mentioned in Laboratory Methods for the Analysis of Microplastics in the Marine Environment: Recommendations for Quantifying Synthetic Particles in Waters and Sediments by the National Oceanic and Atmospheric Administration (NOAA) (Masura et al. 2015). Before the identification of MPs, the mixed solids in the samples were sieved into sizes of 125-300, 300-1000, and 1000-5000 $\mu \mathrm{m}$. After removing the organic contents, hydrogen peroxide $\left(\mathrm{H}_{2} \mathrm{O}_{2}\right.$, Merck KGaA, Germany) and ferrous sulfate ( $\mathrm{FeSO}_{4}$, Ajax Finechem, Australia) in sulfuric acid $\left(\mathrm{H}_{2} \mathrm{SO}_{4}, \mathrm{QReC}\right.$, New Zealand) were used in the wet peroxide oxidation (WPO) process. Sodium chloride ( $\mathrm{NaCl}$, CARLO ERBA, Italy) was added to increase the density of the solution to $1.2 \mathrm{~g} / \mathrm{cm}^{3}$. The filtered saturated $\mathrm{NaCl}$ solution was used for rinsing when the samples were transferred to settling units. MPs were floated on the $\mathrm{NaCl}$ solution while the settled solid was discarded. Although this process cannot float plastics denser than $1.2 \mathrm{~g} / \mathrm{cm}^{3}$ in principle, e.g., polyvinyl chloride (PVC), the $\mathrm{NaCl}$ solution was used because high-density plastics should not float on the surface water, a smaller amount of PVC is produced in comparison with the other light plastics, and $\mathrm{NaCl}$ is more environmentally friendly and economical than the other higher density chemicals, namely sodium tungstate $\left(\mathrm{Na}_{2} \mathrm{WO}_{4}, 1.4 \mathrm{~g} / \mathrm{cm}^{3}\right)$, sodium iodide $\left(\mathrm{Nal}, 1.6 \mathrm{~g} / \mathrm{cm}^{3}\right)$, and zine chloride $\left(\mathrm{ZnCl}_{2}, 1.6-1.7 \mathrm{~g} / \mathrm{cm}^{3}\right)$. Floated MPs were separated from the solution by filtration on a pre-weighted $12 \mu \mathrm{m}$ Nuclepore tracketched membrane (Whatman, 110616). Contamination during analysis was prevented by covering the sample containers with glassware or aluminum foil. In addition, blank samples were checked and adjusted to mitigate contamination during the analytical process. The total number of MPs was counted using a stereomicroscope (Olympus, VMT). Following this, MPs were dried at $60^{\circ} \mathrm{C}$ in an oven and weighed using a five-digit balance (Denver Instrument Company TC-205, U.S.A.). Commercial-grade green polyethylene (PE) with a particle size of 106-212 $\mu \mathrm{m}$ was spiked into the distilled water samples; $121 \%$ and $81 \%$ of the spiked PE particles were recovered from the blank samples and test water samples, respectively. Each dried plasticle was classified according to shape as a fiber (FB), fragment (FR), film $(\mathrm{FI})$, foam $(\mathrm{FM})$, or pellet $(\mathrm{PL})$, with FB referring to a filament, strand line, or fibrous shape; FR referring to 
an irregular shape with a roughly broken surface; FI referring to a thin sheet, film-like particle, or membrane-like particle; FM referring to a piece of sponge, foam-like, or porous material; and PL referring to a group of smooth surfaces having a spherical or an ellipse bead shape. Wood-like particles, the particles that softly broke after pining, were removed during the microscopic count. The MP samples of each shape and sieved size were randomly selected, placed on a $\mathrm{KBr}$ window, and analyzed on the basis of light transmission using a Fourier-transform infrared microscope ( $\mu \mathrm{FTIR}$, Bruker Lumos I, Germany).

\section{Quantification and statistical analysis}

The amount of MP contamination was calculated as "pieces/L" during microscopic counting and "ng/L" during gravimetric analysis. All quantitative data were logarithmically transformed to a normal distribution for parametric statistical testing. The correlation between these units was assessed using Pearson's correlation coefficient. The difference between MPs of different sizes was assessed by $95 \%$ confidence intervals (significance level, 0.05 ) using analysis of variance (ANOVA). Moreover, a post-hoc test with Duncan's equal variances was performed.

\section{Results And Discussion}

\section{Abundance of microplastics in the surface seawater}

In the present study, MPs were detected at each sampling site and sorted into different shapes (Fig. 2). The total abundance of MPs ranged from 1 to 96 pieces/L (corresponding to undetectable-14.17 ng/L), with an average concentration of $9.97 \pm 18.55$ pieces/L (or $1.55 \pm 1.31 \mathrm{ng} / \mathrm{L}$ ). No correlation was noted between the quantitative assessment methods of microscopic counting (pieces/L) and gravimetric analysis $(n g / L)(r=0.05, p=0.723)$. Given the geographic structure of the study area, it can be considered that plastic debris disseminated from the land around three sides and got transported by the circulation of sea water.

Specifically, the water current was assessed during the sampling period. As a result, the water inflow from the eastern side was found to have counterclockwise circulation, a highly chaotic gyre was detected in the southeastern part of the gulf (the GT11, GT20, GT28, GT36, and GT38 areas), and freshwater inflow was detected in the upper area (Maksumpun et al. 2019). By ordinary Kriging interpretation of geostatistical analysis (ArGIS ${ }^{\circledR}$ 10.7.1), the spatial distribution of MPs in the surface water (Fig. 3 ) was found to be as follows: a low concentration in the upper area and a high concentration in the southeast area of the gulf (the highest concentration was detected in the GT28 area). It can be inferred that MPs sourced from the rivers, land, and Middle Gulf of Thailand accumulated in the study area. Previous studies on the transportation of MPs in rivers and estuaries have reported that MPs are transported via river discharge (Xu et al. 2018, Zhao et al. 2015, Zhao et al. 2014, Luo et al. 2019). In addition, a previous study revealed that many small-sized MPs on the high tide line of the beach were formed by the fragmentation of large plastic debris and that the backwash process returned them to the ocean (Fok et al. 2017). It can be assumed that a part of contaminated MPs in the present study was from the rivers 
and the land surrounding the gulf, although MP contamination in these areas was not assessed. However, the water current may transport MPs from external sources. This can be evidenced by the presence of MP contamination in the Antarctic Ocean, where minimal mismanagement of plastic is likely to occur because of the presence of the lowest population in the world (Isobe et al. 2019). Windage (also known as leeway drift), onshore wind, river discharge, and current have been hypothesized to be the key factors contributing to the horizontal transportation of extremely light MPs that float on the surface water, e.g., polystyrene foam $\left(<0.05 \mathrm{~g} / \mathrm{cm}^{3}\right)$ and polyurethane $\left(0.08-0.75 \mathrm{~g} / \mathrm{cm}^{3}\right)$ (Zhang 2017, Chubarenko et al. 2016). Some of the MPs in the present study MPs may have been sourced from the Middle Gulf of Thailand by the southeast inflow current; these MPs could integrate with those from the river or land discharge and accumulate in the gyre. The effects of the water current on MP transportation have also been observed in Greenland gyre; increased MP abundance has been reported in the center of the gyre (Jiang et al. 2020). These findings suggest that MPs in the Inner Gulf of Thailand were transferred by the water current and accumulated in a hotspot gyre. Moreover, the high MP contamination may be caused by the intensive activities at beaches, which are famous tourist destinations; marine transshipments; and industries located in the southeast area.

Although sources of MP contamination are not clearly identified, the total abundance of MPs in the surface water of the Inner Gulf of Thailand was several thousand times higher than that in the open sea (Table 1), e.g., the Bohai Sea of China (Zhang et al. 2017), Baltic Sea of Russia (Zobkov et al. 2019), and Kingston Harbor of Jamaica (Rose and Webber 2019). In this comparison, it must be highlighted that the sampling methods, analytical procedures, and sizes of detected MPs, even though the environment of the study area, were different. The minimum detectable size of MPs directly impacts their abundance detected in the samples. For example, the total abundance of MPs was 7-time-increased when the detected size of MPs was reduced from the size 510-6290 $\mu \mathrm{m}$ in Changjiang Estuary, China (Zhao et al. 2014), to the size of $20-2535 \mu \mathrm{m}$ in small-scale estuaries that stream water to Changjiang Estuary (Zhang et al. 2019). If considered about detectable size variation, the abundance of MPs between different area cannot be competed, but the trend of the investigation should be considered. This study suggests that the minimum size of detected MPs for competition the contamination status between area should be regulated, and the concentrations of MPs can be more accurately determined if smaller sized MPs are analyzed. However, the detectable size of MPs is limited by sampling and analytical procedures because the minimum actual size of MPs samples has been set to $300 \mu \mathrm{m}$ in most studies as the samples have been collected by volume reduction method of neuston nets. 
Table 1

Literature on the comparison of microplastic abundance in global surface waters

\begin{tabular}{|c|c|c|c|}
\hline Study Area & $\begin{array}{l}\text { Size } \\
(\mathrm{mm})\end{array}$ & $\begin{array}{l}\text { Average Concentration } \\
\text { (pieces/L) }\end{array}$ & Reference \\
\hline Bohai Sea, China & $0.3-5$ & $3.3 \times 10^{-4}$ & (Zhang et al. 2017) \\
\hline Changjiang Estuary, China & $0.51-6.29$ & 4.137 & (Zhao et al. 2014) \\
\hline East China Sea, China & $0.5-12.46$ & $1.67 \times 10^{-4}$ & (Zhao et al. 2014) \\
\hline Baltic Sea, Russia & no report & $3.2 \times 10^{-2}$ & (Zobkov et al. 2019) \\
\hline Kingston Harbor, Jamaica & $0.3-5$ & $7.6 \times 10^{-4}$ & (Rose and Webber 2019) \\
\hline Small-Scale Estuaries, China & $0.02-2.54$ & 27.84 & (Zhang et al. 2019) \\
\hline Bay of Brest, France & $0.3-5$ & $2.4 \times 10^{-4}$ & (Frere et al. 2017) \\
\hline $\begin{array}{l}\text { North Sea Coast, The } \\
\text { Netherlands }\end{array}$ & no report & 27.00 & (Karlsson et al. 2017) \\
\hline North Yellow Sea, China & $0.03-5$ & 0.545 & (Zhu et al. 2018) \\
\hline Ciwalengke River, Indonesia & $0.05-2$ & 5.85 & (Alam et al. 2019) \\
\hline Charleston Harbor, U.S.A. & $0.063-2$ & 6.6 & (Gray et al. 2018) \\
\hline Winyah Bay, U.S.A. & $0.063-2$ & 30.8 & (Gray et al. 2018) \\
\hline Surabaya, Indonesia & $0.2-5$ & 0.49 & (Cordova et al. 2019) \\
\hline Kuala Nerus, Malaysia & $0.02-5$ & $0.69 *$ & (Khalik et al. 2018) \\
\hline Greenland Sea Gyre & $0.1-5$ & 2.43 & (Jiang et al. 2020) \\
\hline The Inner Gulf of Thailand & $0.125-5$ & 9.97 & The present study \\
\hline
\end{tabular}

\section{Physical characteristics of microplastics}

In the present study, MPs with sizes ranging from 125 to $5000 \mu \mathrm{m}$ were detected. Most detected MPs were sized $125-300 \mu \mathrm{m}$ (68\% of the pieces) and $300-1000 \mu \mathrm{m}$ ( $22 \%$ of the pieces). Contamination with MPs (pieces/L) sized 125-300 $\mu \mathrm{m}$ was significantly higher than that with MPs sized $1000-5000 \mu \mathrm{m}(\mathrm{p}=$ 0.019) (Fig. 4a). Surprisingly, the percentage of MP as per size was different when the unit "ng/L" was considered; however, the size distribution of MPs was the same trend which high proportion in the size 125-300 $\mu \mathrm{m}$. The number of MPs was not related to gravimetrical weight, with respect to the abundance of MPs, there were no significant differences between the sizes in $n g / L(p=0.323)$ (Fig. $4 b)$. Moreover, MPs smaller than each size of the sieve (125-300,300-1000, and 1000-5000 $\mu \mathrm{m}$ ) were detected in all the samples. This result suggests the accumulation of small-sized MPs in suspended particulate matter. 
The predominant shape of MPs was assessed for each particle size (Fig. 5). Overall, FB (35\%), FR (34\%), and $\mathrm{FI}(27 \%)$ were the predominant shapes of MPs, while FM $(2 \%)$ and PL $(2 \%)$ were rarely observed. Furthermore, small film plastics sized less than $1000 \mu \mathrm{m}$ were extremely found when the sieved sample size was 1000-5000 $\mu \mathrm{m}$. As shown in Fig. 2c, large-sized MPs (1000-5000 $\mu \mathrm{m})$ and small film particles $(<1000 \mu \mathrm{m})$ were observed when the sieved sample size was $1000-5000 \mu \mathrm{m}$. The detected smaller size of MPs than the size of sieved samples may be affected from either aggregation of small MPs to large particles in samples or fragmentation of large MPs to smaller during sample preparation. Although the dynamic in size of MPs should be study, the high abundance of small-sized fragments among MPs was investigated and it may have resulted from fragmented MPs or secondary MPs.

After confirming that the detected particles were plastics, MPs $(42,69,28,20$, and 7 pieces having the FB, $\mathrm{FI}, \mathrm{FR}, \mathrm{FM}$, and PL shapes, respectively) were sampled for qualitative analysis. The result revealed that PE was the major plastic component in the samples (27\%). Poly(ethylene:propylene) (PE/PP), PP, ethylenepropylene diene monomer (EPDM) rubber, and other plastics [styrene-ethylene-butylene-styrene (SEBS), polyacrylate derivatives, and polyamide (PA)] were identified in $21 \%, 16 \%, 12 \%$, and $23 \%$ of the samples, respectively (Fig. 6a). Notably, PVC $(0.2 \%)$ and cotton mixed with nylon $(0.2 \%)$ were also found in the samples. However, only four pieces of nonplastic particles (1.4\%) were identified (cotton and maltodextrin). The polymer types were specifically investigated in MPs of various shapes. PE was the main polymer type in MPs having $\mathrm{FI}$ and $\mathrm{FR}$ shapes. PE/PP, ethylene vinyl acetate (EVA), and poly(amidoamine) (PAMAM) were the main polymer types in MPs having FB, FM, and PL shapes, respectively (Fig. 6b-f).

\section{Polymer identification}

The FTIR spectra of the main plastic types are shown in Fig. 7. The FTIR spectra of PE, PE/PP, and PP were assessed as these were the three most abundant polymers detected in the samples in the present study, while those of EVA and PAMAM were assessed as these were the predominant polymers detected in FM and PL samples. The $4000-1500 \mathrm{~cm}^{-1}$ spectral region was selected for the vibration of the general functional groups in the polymers. Representing alkane structures, peaks of C-H stretching (3000-2850 $\left.\mathrm{cm}^{-1}\right)$ and $-\mathrm{CH}_{2}$ blending $\left(1465 \mathrm{~cm}^{-1}\right)$ were detected in all the identified plastic samples. The fingerprint region (1450-600 $\mathrm{cm}^{-1}$ ) was specifically characterized to determine the chemical structure of the polymer; this region and the functional region were compared to the polymer reference database. For instance, the spectrum at wavenumber $718 \mathrm{~cm}^{-1}$ with $\mathrm{C}-\mathrm{H}$ stretching $\left(3000-2850 \mathrm{~cm}^{-1}\right)$ and $-\mathrm{CH}_{2}$ blending $\left(1465 \mathrm{~cm}^{-1}\right.$ ) was the fingerprint of PE (Da Costa et al. 2018). In addition, the spectrum of $-\mathrm{CH}_{3}$ blending $\left(1380 \mathrm{~cm}^{-1}\right)$ was the determinant of the functional group of $-\mathrm{CH}_{3}$ in propylene present in PP and PE/PP. Moreover, the spectrum of $\mathrm{C}=0$ stretching $\left(1760-1670 \mathrm{~cm}^{-1}\right)$ and $\mathrm{C}-0$ stretching $(1260-1000$ $\mathrm{cm}^{-1}$ ) was the determinant of the vinyl acetate group present in EVA, while the spectrum of the amide group that included $\mathrm{N}-\mathrm{H}$ blending $\left(1640 \mathrm{~cm}^{-1}\right), \mathrm{N}-\mathrm{H}$ stretching $\left(3500-3100 \mathrm{~cm}^{-1}\right)$, and $\mathrm{C}=\mathrm{O}$ of amide stretching was the fingerprint of PAMAM. 
The FTIR spectrum could reveal the status of plastic fragmentation as a marker of the presence of new oxidized groups in the polymer structure. A strong evidence is the detection of weak broad peaks of $\mathrm{C}=0$ stretching $\left(1760-1670 \mathrm{~cm}^{-1}\right)$, C-O stretching $\left(1050 \mathrm{~cm}^{-1}\right)$, and $-\mathrm{OH}$ blending $\left(3330-3370 \mathrm{~cm}^{-1}\right)$ as new functional groups of PE in FR samples. These markers correspond to oxidized groups and decrease the formation of native peaks of degraded PE (Da Costa et al. 2018). Interestingly, oxidized groups were less frequently observed in PL samples. Moreover, there was no or a very small amount of PL observed in large-sized MPs. This result suggests that PL-shaped MPs can be referred to as primary MPs, e.g., PAMAM used in drug delivery. In general, the polymer types of MPs may reflect the utilization patterns of plastic products and the mismanagement of plastic waste. For instance, PE is the common component of plastic bags and containers (Crawford and Quinn 2017). With respect to marine plastic debris composition, the Pollution Control Department of Thailand has reported that plastic bags (mostly PE) account for $33.4 \%$ of the debris accumulated on beaches, coral reefs, and mangrove areas (Pollution Control Department 2019). Thus, there is high potential for such plastic debris to enter the sea and be transformed into MPs.

\section{Impacts of environment factor on microplastic contamination}

In the present study, we noted physical and chemical variation in the plastic debris. The deterioration of plastic litter, which makes the plastic yellow and brittle, is caused by complex changes in oxidative reactions induced by UV radicals, temperature differences, oxygen changes, and oxidative free radicals. Furthermore, large plastic debris can be broken down into small plasticles by mechanical force from wave turbulence, rock or sand encounters, and animal grinding (Andrady 2011, Andrady 2017). Thus, plastic litter is susceptible to fragmentation in beach and surface waters, where these inducing factors are present. As a result of fragmentation, MPs sized less than $1.0 \mathrm{~mm}$ have been found to be predominant in beach and surface waters in previous studies; however, the minimum sizes could not be clarified because of limitations in the analyses (Zhao et al. 2015, Zhao et al. 2014, Luo et al. 2019, Fok et al. 2017, Zhang et al. 2017, Laglbauer et al. 2014). A previous study has also revealed that plastic may be fragmented into smaller sizes during the organic content removal process (Nuelle et al. 2014). The small plasticles observed in large-sized particles in the present study may be explained by the integration between MPs and natural nonplastic particles, which may have increased their actual size in the samples. A previous study reported the formation of biofilms on submerged PE food bags in the marine environment after a week, with levels increasing throughout the 3 weeks of the experimental process (Lobelle and Cunliffe 2011). Studies on the interaction between MPs and phytoplankton have revealed the hetero-aggregation course of extracellular polysaccharides in diatoms and dissolved organic carbon obtained from the lysis of algae (Long et al. 2015, Long et al. 2017). After 12 weeks of exposure to the sea surface, plastics have been found to be covered with diatoms and algae, affecting the magnitude of their higher mass (Fazey and Ryan 2016). Because of structural degradation and complex formation, MPs are induced to be variably transported and transformed into other pollutants.

The transportation of MPs has been shown to be impacted by surrounding factors and by the properties of MPs, including their sizes, shapes, and chemical structures. MP contamination in the surface water of 
the Inner Gulf of Thailand may be the result of anthropogenic activities around the gulf. The correlation between MP contamination in estuarine environments as a result of urban activities and the population density was not significant; however, the contamination may be related to the economic structure (Zhao et al. 2015). In our study area, MPs may have been sourced from the main rivers above the Inner Gulf of Thailand that included the pollution load from inland cities and industries. In a previous study, before the transportation of MPs to the open sea, a higher level of MP contamination was detected in creeks and rivers passing urban areas, with the levels in estuaries becoming higher than those in the coastal seawater (Zhao et al. 2014, Luo et al. 2019). In another study, no significant concentrations of MPs were recorded before and after typhoon activity, indicating that MP contamination may be influenced by source discharge, river flow, and vertical mixing (Zhao et al. 2015). A study assessing the distribution of MPs in the surface water of the Changjiang River Estuary revealed that the concentration of MPs decreased as a result of freshwater dilution and the warm current in the study area (Xu et al. 2018). On the other hand, sinking MPs that had a spherical shape exhibited rotation, oscillation, and tumbling movements; the settling velocity depended on the plastic type, shape, and size and salinity (Kowalski et al. 2016, Khatmullina and Isachenko 2017). Overall, the concentration of settled plastics depended on their density. For example, the sinking velocity of PVC $\left(1.56 \mathrm{~g} / \mathrm{cm}^{3}\right)$ was found to be higher than that of polystyrene $\left(1.14 \mathrm{~g} / \mathrm{cm}^{3}\right.$ ) (Kowalski et al. 2016). In addition, the negative buoyancy of MPs has been shown to be increased by aggregation with biofouling (Fazey and Ryan 2016). Accordingly, MP stratification has been found to fluctuate in water columns (Zobkov et al. 2019). In study on algal attachment on the MP surface, MPs exhibited an up and down oscillatory pattern for vertical movement in a water column (Kooi et al. 2017). Unlike natural solids, the behavior of MPs may be specific to circumstances and differ accordingly. However, the impacts of MP contamination are variable and complex.

In addition to the persistence of MPs, their chemical additives and adherence characteristics should be focused on as a function of their toxicity. The environmental and human health hazard rankings of plastic polymers have been finalized on the basis of their chemical compositions (Lithner et al. 2011), and they have been used to assess the risk of MP contamination in the surface water and sediment (Xu et al. 2018, Peng et al. 2018). Nevertheless, the risk of MPs is not just because of additives. Field monitoring and experiments have revealed that the persistence of organic pollutants and heavy metals can be a product of both plastic components and adherents on the surface of MPs (Rochman et al. 2013, Rochman et al. 2014, Wang et al. 2017, Van et al. 2012, Zhang et al. 2015, Heskett et al. 2012, Antunes et al. 2013, Holmes et al. 2012). An MP extraction test demonstrating the synthetic digestive characteristics of the seabird Fulmarus glacialis revealed that the inorganic elements in plastic were released after 168$220 \mathrm{~h}$ of extraction (Massos and Turner 2017, Turner and Lau 2016, Turner 2017). While the effects of MPs and their co-contaminants have not been clearly described, their toxicity may be controlled by the environment.

Although the threshold of MP toxicity has not been assessed, the concentration of contaminating MPs represents the dose to which the susceptible community is probably exposed. In the present study, MPs 
contaminating the surface water of the Inner Gulf of Thailand were found to contain a high fraction of small-sized fragmented plasticles. Environmental interaction has been discussed as a factor that accelerates the degradation of MPs to a smaller size and their aggregation to natural solid particles. The fate and transportation of MPs are important mechanisms responsible for their movement and toxicity in the ecosystem. Given the increasing prevalence of MPs, their unknown properties need to be identified in future studies.

\section{Conclusion}

The present study is the first to report MP contamination in the surface water of the Inner Gulf of Thailand. MPs were detected at an average concentration of $9.97 \pm 18.55$ pieces/L (or $1.55 \pm 1.31 \mathrm{ng} / \mathrm{L}$ ) in the study area. Although the minimum detectable size was limited to $125 \mu \mathrm{m}$ during the sampling process, the detection of MPs is reflective of the fragmentation of marine plastic debris. Overall, the debris was assumed to be loaded into the gulf as results of both land-based activities by river transportation and marine-based activities by current transportation. Following this, the debris was fragmented to form MPs. Based on this hypothesis, river estuaries are a hotspot for plasticle deposits. At the same time, the Inner Gulf of Thailand is subject to the accumulation of sinking pollutants. The physical and chemical compositions of plastic debris may be transformed during river discharge and marine accumulation. In future studies, qualitative and quantitative analyses of the influence of seasonal change on the loading and accumulation of MPs in both major river estuaries and the Inner Gulf of Thailand may help understand the fate and transportation of MPs. The toxicity of MPs also needs to be clarified in future studies. It should be noted that the contaminating plastic debris will be degraded into smaller MPs and these may have higher availability in terms of toxic adsorption and release. The key concern to be addressed is whether such contamination will pollute or pose further risks to the ecosystem.

\section{Declarations}

\section{Acknowledgments}

The authors acknowledge the research team at the Department of Marine Science, Faculty of Fishery, Kasetsart University for the sample collection. The present study was funded by Chulalongkorn University CU_GR_63_04_23_02 and the Ratchadapisek Sompoch Endowment Fund (2020) under Microplastic and Plastic Waste Cluster, Chulalongkorn University. In addition, this work was supported by the $100^{\text {th }}$ Anniversary Chulalongkorn University Doctoral Scholarship; the $90^{\text {th }}$ Anniversary of Chulalongkorn University Fund (Ratchadaphiseksomphot Endowment Fund); and the Department of Environmental Science, Faculty of Science, Chulalongkorn University.

\section{Ethics approval and consent to participate:}

Not applicable. 


\section{Consent for publication:}

Not applicable.

\section{Availability of data and materials:}

All data generated or analyzed during this study are included in this published article [and its

Supplementary files are not available with this version]

\section{Competing interests:}

The authors declare that they have no competing interests.

\section{Funding:}

The present research was funded by Chulalongkorn University, Thailand. the funding details are mentioned in acknowledgements.

\section{Authors' contributions:}

PV collected the surface water, characterized microplastics, wrote manuscript.

SS planed research project and edited manuscript.

All authors read and approved the final manuscript.

\section{References}

1. Alam FC, Sembiring E, Muntalif BS and Suendo V (2019) Microplastic distribution in surface water and sediment river around slum and industrial area (case study: Ciwalengke River, Majalaya district, Indonesia). Chemosphere 224: 637-645. https://doi.org/10.1016/j.chemosphere.2019.02.188

2. Anbumani S and Kakkar P (2018) Ecotoxicological effects of microplastics on biota: a review. Environmental Science and Pollution Reseach 25: 14373-14396. https://doi.org/10.1007/s11356018-1999-x

3. Andrady AL (2011) Microplastics in the marine environment. Mar. Pollut. Bull. 62: 1596-1605. https://doi.org/10.1016/j.marpolbul.2011.05.030

4. Andrady AL (2017) The plastic in microplastics: A review. Mar. Pollut. Bull. 119: 12-22. https://doi.org/10.1016/j.marpolbul.2017.01.082

5. Antunes JC, Frias JGL, Micaelo AC and Sobral P (2013) Resin pellets from beaches of the Portuguese coast and adsorbed persistent organic pollutants. Estuarine, Coastal and Shelf Science 130: 62-69. https://doi.org/10.1016/j.ecss.2013.06.016

6. Ashton K, Holmes L and Turner A (2010) Association of metals with plastic production pellets in the marine environment. Mar. Pollut. Bull. 60: 2050-2055. https://doi.org/10.1016/j.marpolbul.2010.07.014

7. Buranapratheprat A (2008) Circulation in the upper gulf of Thailand: A review. Burapha Science Journal 13: 75-83. 
8. Chubarenko I, Bagaev A, Zobkov M and Esiukova E (2016) On some physical and dynamical properties of microplastic particles in marine environment. Mar. Pollut. Bull. 108: 105-112. https://doi.org/10.1016/j.marpolbul.2016.04.048

9. Cole M, Lindeque P, Halsband C and Galloway TS (2011) Microplastics as contaminants in the marine environment: a review. Mar. Pollut. Bull. 62: 2588-2597. https://doi.org/10.1016/j.marpolbul.2011.09.025

10. Cordova MR, Purwiyanto AIS and Suteja Y (2019) Abundance and characteristics of microplastics in the northern coastal waters of Surabaya, Indonesia. Mar. Pollut. Bull. 142: 183-188. https://doi.org/10.1016/j.marpolbul.2019.03.040

11. Crawford CB and Quinn B (2017) Microplastic Pollutants. Candice G.Janco,

12. Da Costa JP, Nunes AR, Santos PSM, Girao AV, Duarte AC and Rocha-Santos $T$ (2018) Degradation of polyethylene microplastics in seawater: Insights into the environmental degradation of polymers. Journal of Environmental Science and Health, part A Toxic/Hazardous Substances and Environmental Engineering 53: 866-875. https://doi.org/10.1080/10934529.2018.1455381

13. Fazey FM and Ryan PG (2016) Biofouling on buoyant marine plastics: An experimental study into the effect of size on surface longevity. Environ. Pollut. 210: 354-360. https://doi.org/10.1016/j.envpol.2016.01.026

14. Fok L, Cheung PK, Tang G and Li WC (2017) Size distribution of stranded small plastic debris on the coast of Guangdong, South China. Environ. Pollut. 220: 407-412. https://doi.org/10.1016/j.envpol.2016.09.079

15. Frere L, Paul-Pont I, Rinnert E, Petton S, Jaffre J, Bihannic I, Soudant P et al. (2017) Influence of environmental and anthropogenic factors on the composition, concentration and spatial distribution of microplastics: A case study of the Bay of Brest (Brittany, France). Environ. Pollut. 225: 211-222. https://doi.org/10.1016/j.envpol.2017.03.023

16. Gray AD, Wertz H, Leads RR and Weinstein JE (2018) Microplastic in two South Carolina Estuaries: Occurrence, distribution, and composition. Mar. Pollut. Bull. 128: 223-233. https://doi.org/10.1016/j.marpolbul.2018.01.030

17. Hahladakis JN, Velis CA, Weber R, lacovidou E and Purnell P (2018) An overview of chemical additives present in plastics: Migration, release, fate and environmental impact during their use, disposal and recycling. J. Hazard. Mater. 344: 179-199. https://doi.org/10.1016/j.jhazmat.2017.10.014

18. Heskett M, Takada H, Yamashita R, Yuyama M, Ito M, Geok YB, Ogata Y et al. (2012) Measurement of persistent organic pollutants (POPs) in plastic resin pellets from remote islands: toward establishment of background concentrations for International Pellet Watch. Mar. Pollut. Bull. 64: 445448. https://doi.org/10.1016/j.marpolbul.2011.11.004

19. Hidalgo-Ruz V, Gutow L, Thompson RC and Thiel M (2012) Microplastics in the marine environment: a review of the methods used for identification and quantification. Environmental Science \& Technology 46: 3060-3075. https://doi.org/10.1021/es2031505 
20. Holmes LA, Turner A and Thompson RC (2012) Adsorption of trace metals to plastic resin pellets in the marine environment. Environ. Pollut. 160: 42-48. https://doi.org/10.1016/j.envpol.2011.08.052

21. Huffer T, Weniger AK and Hofmann T (2018) Sorption of organic compounds by aged polystyrene microplastic particles. Environ. Pollut. 236: 218-225. https://doi.org/10.1016/j.envpol.2018.01.022

22. Isobe A, Uchiyama-Matsumoto K, Uchida K and Tokai T (2019) Microplastics in the Southern Ocean. Mar. Pollut. Bull. 114: 623-626. https://doi.org/10.1016/j.marpolbul.2016.09.037

23. Jambeck JR, Geyer R, Wilcox C, Siegler TR, Perryman M, Andrady A, Narayan R et al. (2015) Plastic waste inputs from land into the ocean. Science 347: 768-771.

24. Jiang Y, Yang F, Zhao Y and Wang J (2020) Greenland Sea Gyre increases microplastic pollution in the surface waters of the Nordic Seas. Sci. Total Environ. 712: 1-9.

https://doi.org/10.1016/j.scitotenv.2019.136484

25. Karlsson TM, Vethaak AD, Almroth BC, Ariese F, van Velzen M, Hassellov M and Leslie HA (2017) Screening for microplastics in sediment, water, marine invertebrates and fish: Method development and microplastic accumulation. Mar. Pollut. Bull. 122: 403-408.

https://doi.org/10.1016/j.marpolbul.2017.06.081

26. Khalik WMAWM, Ibrahim YS, Anuar ST, Govindasamy S and Baharuddin NF (2018) Microplastics analysis in Malaysian marine waters: A field study of Kuala Nerus and Kuantan. Mar. Pollut. Bull. 135: 451-457. https://doi.org/10.1016/j.marpolbul.2018.07.052

27. Khatmullina $L$ and Isachenko I (2017) Settling velocity of microplastic particles of regular shapes. Mar. Pollut. Bull. 114: 871-880. https://doi.org/10.1016/j.marpolbul.2016.11.024

28. Koelmans AA, Bakir A, Burton GA and Janssen CR (2016) Microplastic as a vector for chemicals in the aquatic environment: Critical review and model-supported reinterpretation of empirical studies. Environmental Science \& Technology 50: 3315-3326. https://doi.org/10.1021/acs.est.5b06069

29. Kooi M, Nes EHV, Scheffer M and Koelmans AA (2017) Ups and downs in the ocean: effects of biofouling on vertical transport of microplastics. Environmental Science \& Technology 51: 79637971. https://doi.org/10.1021/acs.est.6b04702

30. Kowalski N, Reichardt AM and Waniek JJ (2016) Sinking rates of microplastics and potential implications of their alteration by physical, biological, and chemical factors. Mar. Pollut. Bull. 109: 310-319. https://doi.org/10.1016/j.marpolbul.2016.05.064

31. Laglbauer BJL, Franco-Santos RM, Andreu-Cazenave M, Brunelli L, Papadatou M, Palatinus A, Grego $M$ et al. (2014) Macrodebris and microplastics from beaches in Slovenia. Mar. Pollut. Bull. 89: 356366. https://doi.org/10.1016/j.marpolbul.2014.09.036

32. Lithner D, Larsson A and Dave G (2011) Environmental and health hazard ranking and assessment of plastic polymers based on chemical composition. Sci. Total Environ. 409: 3309-3324. https://doi.org/10.1016/j.scitotenv.2011.04.038

33. Lobelle D and Cunliffe M (2011) Early microbial biofilm formation on marine plastic debris. Mar. Pollut. Bull. 62: 197-200. https://doi.org/10.1016/j.marpolbul.2010.10.013 
34. Long M, Moriceau B, Gallinari M, Lambert C, Huvet A, Raffray J and Soudant P (2015) Interactions between microplastics and phytoplankton aggregates: Impact on their respective fates. Mar. Chem. 175: 39-46. https://doi.org/10.1016/j.marchem.2015.04.003

35. Long M, Paul-Pont I, Hegaret H, Moriceau B, Lambert C, Huvet A and Soudant P (2017) Interactions between polystyrene microplastics and marine phytoplankton lead to species-specific heteroaggregation. Environ. Pollut. 228: 454-463. https://doi.org/10.1016/j.envpol.2017.05.047

36. Luo W, Su L, Craig NJ, Du F, Wu C and Shi H (2019) Comparison of microplastic pollution in different water bodies from urban creeks to coastal waters. Environ. Pollut. 246: 174-182. https://doi.org/10.1016/j.envpol.2018.11.081

37. Maksumpun S, Phaksopa J, Thaipichitburapa P, Srithongouthai S, Sirinawin W, Pokavanich T, Thawonsode $\mathrm{N}$ et al. (2019) Development of Socio-Ecological Based Effective Fishery Management Policy for Good Governance in Sustainable Fishery of the Inner Gulf of Thailand: Assessments of Impacts from Climate Changes and Specific Hydro-ecological Characteristics of surrounded Estuaries on the Water Quality and Pollution Status of the Inner Gulf of Thailand. (in Thai)

38. Mao Y, Ai H, Chen Y, Zhang Z, Zeng P, Kang L, Li W et al. (2018) Phytoplankton response to polystyrene microplastics: Perspective from an entire growth period. Chemosphere 208: 59-68. https://doi.org/10.1016/j.chemosphere.2018.05.170

39. Massos A and Turner A (2017) Cadmium, lead and bromine in beached microplastics. Environ. Pollut. 227: 139-145. https://doi.org/10.1016/j.envpol.2017.04.034

40. Masura J, Baker J, Foster G and Arthur C (2015) Laboratory method for the analysis of microplastics in the marine environment: recommendations for quantifying synthetic particles in waters and sediments.

41. Matsuguma Y, Takada H, Kumata H, Kanke H, Sakurai S, Suzuki T, Itoh M et al. (2017) Microplastics in sediment cores from asia and africa as indicators of temporal trends in plastic pollution. Archives of Environmental Contamination and Toxicology 73: 230-239. https://doi.org/10.1007/s00244-0170414-9

42. Munier B and Bendell LI (2018) Macro and micro plastics sorb and desorb metals and act as a point source of trace metals to coastal ecosystems. PLoS One 13: 1-13. https://doi.org/10.1371/journal.pone.0191759

43. Nuelle MT, Dekiff JH, Remy D and Fries E (2014) A new analytical approach for monitoring microplastics in marine sediments. Environ. Pollut. 184: 161-169. https://doi.org/10.1016/j.envpol.2013.07.027

44. Peng G, Xu P, Zhu B, Bai M and Li D (2018) Microplastics in freshwater river sediments in Shanghai, China: A case study of risk assessment in mega-cities. Environ. Pollut. 234: 448-456. https://doi.org/10.1016/j.envpol.2017.11.034

45. Pollution Control Department (2019) Booklet on Thailand State of Pollution 2018: Minitry of Natural Resource and Environment. 
46. Rochman CM, Hentschel BT and Teh SJ (2014) Long-term sorption of metals is similar among plastic types: implications for plastic debris in aquatic environments. PLoS One 9: 1-10. https://doi.org/10.1371/journal.pone.0085433

47. Rochman CM, Hoh E, Hentschel BT and Kaye S (2013) Long-term field measurement of sorption of organic contaminants to five types of plastic pellets: implications for plastic marine debris. Environmental Science \& Technology 47: 1646-1654. https://doi.org/10.1021/es303700s

48. Rose D and Webber M (2019) Characterization of microplastics in the surface waters of Kingston Harbour. Sci. Total Environ. 664: 753-760. https://doi.org/10.1016/j.scitotenv.2019.01.319

49. Thushari GGN, Senevirathna JDM, Yakupitiyage A and Chavanich S (2017) Effects of microplastics on sessile invertebrates in the eastern coast of Thailand: An approach to coastal zone conservation. Mar. Pollut. Bull. 124: 349-355. https://doi.org/10.1016/j.marpolbul.2017.06.010

50. Turner A (2017) Trace elements in fragments of fishing net and other filamentous plastic litter from two beaches in SW England. Environ. Pollut. 224: 722-728.

https://doi.org/10.1016/j.envpol.2016.11.034

51. Turner A and Lau KS (2016) Elemental concentrations and bioaccessibilities in beached plastic foam litter, with particular reference to lead in polyurethane. Mar. Pollut. Bull. 112: 265-270. https://doi.org/10.1016/j.marpolbul.2016.08.005

52. Van A, Rochman CM, Flores EM, Hill KL, Vargas E, Vargas SA and Hoh E (2012) Persistent organic pollutants in plastic marine debris found on beaches in San Diego, California. Chemosphere 86: 258263. https://doi.org/10.1016/j.chemosphere.2011.09.039

53. Wang J, Peng J, Tan Z, Gao Y, Zhan Z, Chen Q and Cai L (2017) Microplastics in the surface sediments from the Beijiang River littoral zone: Composition, abundance, surface textures and interaction with heavy metals. Chemosphere 171: 248-258. https://doi.org/10.1016/j.chemosphere.2016.12.074

54. Wang J, Tan Z, Peng J, Qiu Q and Li M (2016) The behaviors of microplastics in the marine environment. Marine Environmental Research 113: 7-17.

https://doi.org/10.1016/j.marenvres.2015.10.014

55. Wang W and Wang J (2018) Different partition of polycyclic aromatic hydrocarbon on environmental particulates in freshwater: Microplastics in comparison to natural sediment. Ecotoxicology Environmental Safety 147: 648-655. https://doi.org/10.1016/j.ecoenv.2017.09.029

56. Xu P, Peng G, Su L, Gao Y, Gao L and Li D (2018) Microplastic risk assessment in surface waters: A case study in the Changjiang Estuary, China. Mar. Pollut. Bull. 133: 647-654. https://doi.org/10.1016/j.marpolbul.2018.06.020

57. Zhang H (2017) Transport of microplastics in coastal seas. Estuarine, Coastal and Shelf Science 199: 74-86. https://doi.org/10.1016/j.ecss.2017.09.032

58. Zhang J, Zhang C, Deng Y, Wang R, Ma E, Wang J, Bai J et al. (2019) Microplastics in the surface water of small-scale estuaries in Shanghai. Mar. Pollut. Bull. 149: 1-6. https://doi.org/10.1016/j.marpolbul.2019.110569 
59. Zhang W, Ma X, Zhang Z, Wang Y, Wang J, Wang J and Ma D (2015) Persistent organic pollutants carried on plastic resin pellets from two beaches in China. Mar. Pollut. Bull. 99: 28-34. https://doi.org/10.1016/j.marpolbul.2015.08.002

60. Zhang W, Zhang S, Wang J, Wang Y, Mu J, Wang P, Lin X et al. (2017) Microplastic pollution in the surface waters of the Bohai Sea, China. Environ. Pollut. 231: 541-548.

https://doi.org/10.1016/j.envpol.2017.08.058

61. Zhao S, Zhu L and Li D (2015) Microplastic in three urban estuaries, China. Environ. Pollut. 206: 597604. https://doi.org/10.1016/j.envpol.2015.08.027

62. Zhao S, Zhu L, Wang T and Li D (2014) Suspended microplastics in the surface water of the Yangtze Estuary System, China: first observations on occurrence, distribution. Mar. Pollut. Bull. 86: 562-568. https://doi.org/10.1016/j.marpolbul.2014.06.032

63. Zhu L, Bai H, Chen B, Sun X, Qu K and Xia B (2018) Microplastic pollution in North Yellow Sea, China: Observations on occurrence, distribution and identification. Sci. Total Environ. 636: 20-29. https://doi.org/10.1016/j.scitotenv.2018.04.182

64. Zobkov MB, Esiukova EE, Zyubin AY and Samusev IG (2019) Microplastic content variation in water column: The observations employing a novel sampling tool in stratified Baltic Sea. Mar. Pollut. Bull. 138: 193-205. https://doi.org/10.1016/j.marpolbul.2018.11.047

\section{Figures}
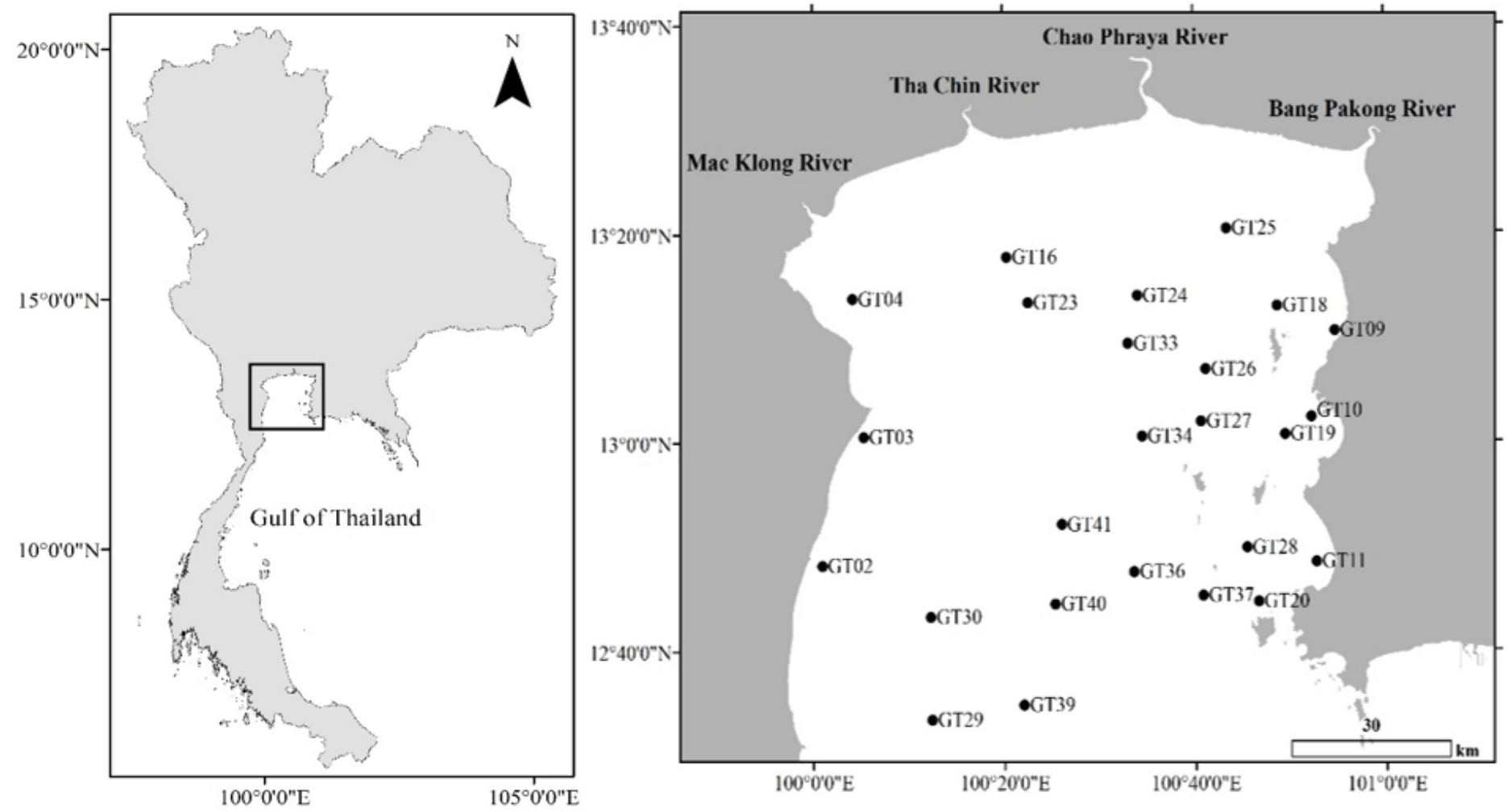

Figure 1 
Microplastic sampling points in the Inner Gulf of Thailand, South China Sea, Pacific Ocean Note: The designations employed and the presentation of the material on this map do not imply the expression of any opinion whatsoever on the part of Research Square concerning the legal status of any country, territory, city or area or of its authorities, or concerning the delimitation of its frontiers or boundaries. This map has been provided by the authors.
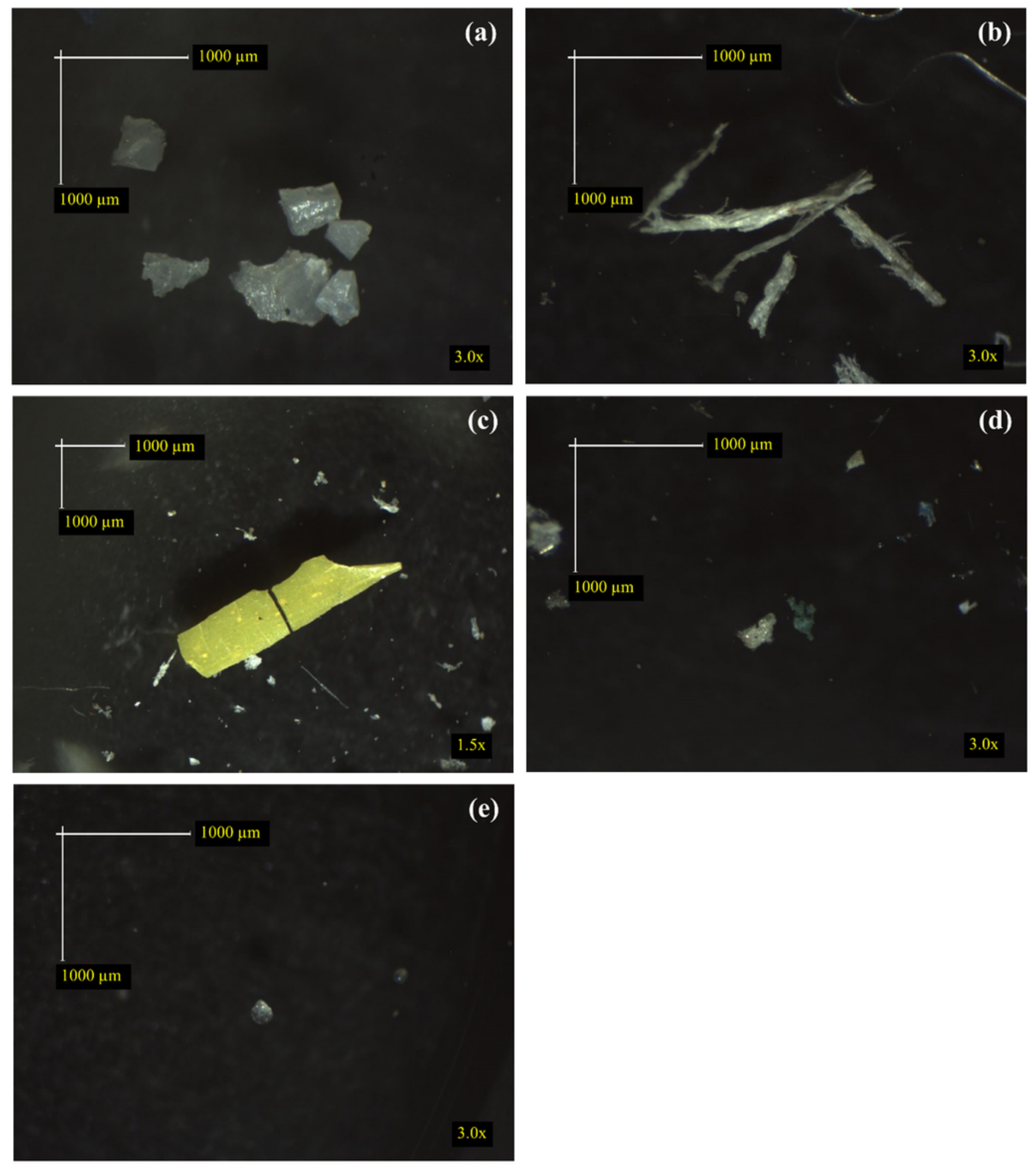

Figure 2 
Photographs of microplastic shapes identified in the surface water of the Inner Gulf of Thailand: (a) fragment, (b) fiber, (c) film, (d) foam, and (e) pellet

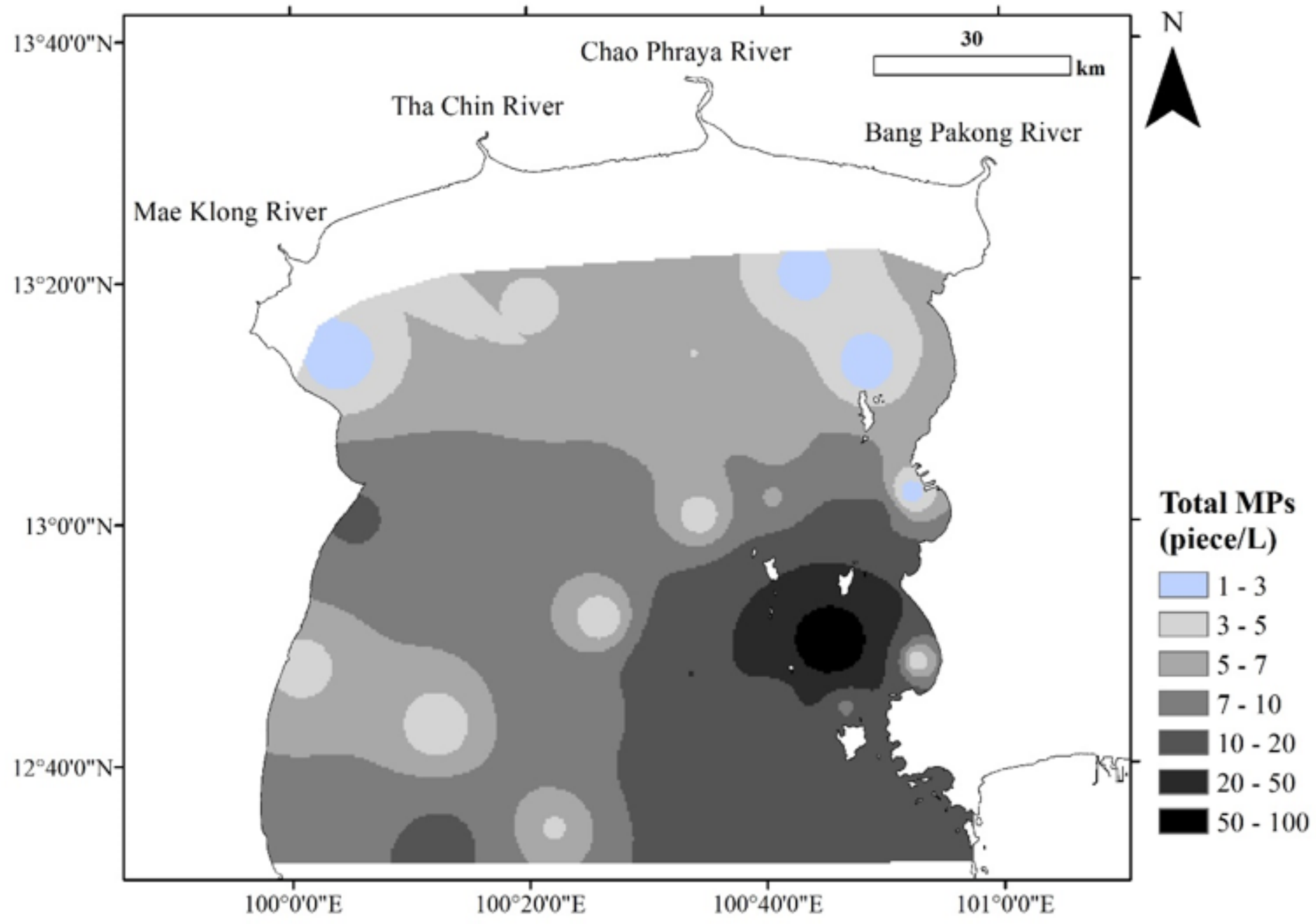

\section{Figure 3}

Spatial distribution of total microplastics in the surface water of the Inner Gulf of Thailand Note: The designations employed and the presentation of the material on this map do not imply the expression of any opinion whatsoever on the part of Research Square concerning the legal status of any country, territory, city or area or of its authorities, or concerning the delimitation of its frontiers or boundaries. This map has been provided by the authors. 
(a)

(b)
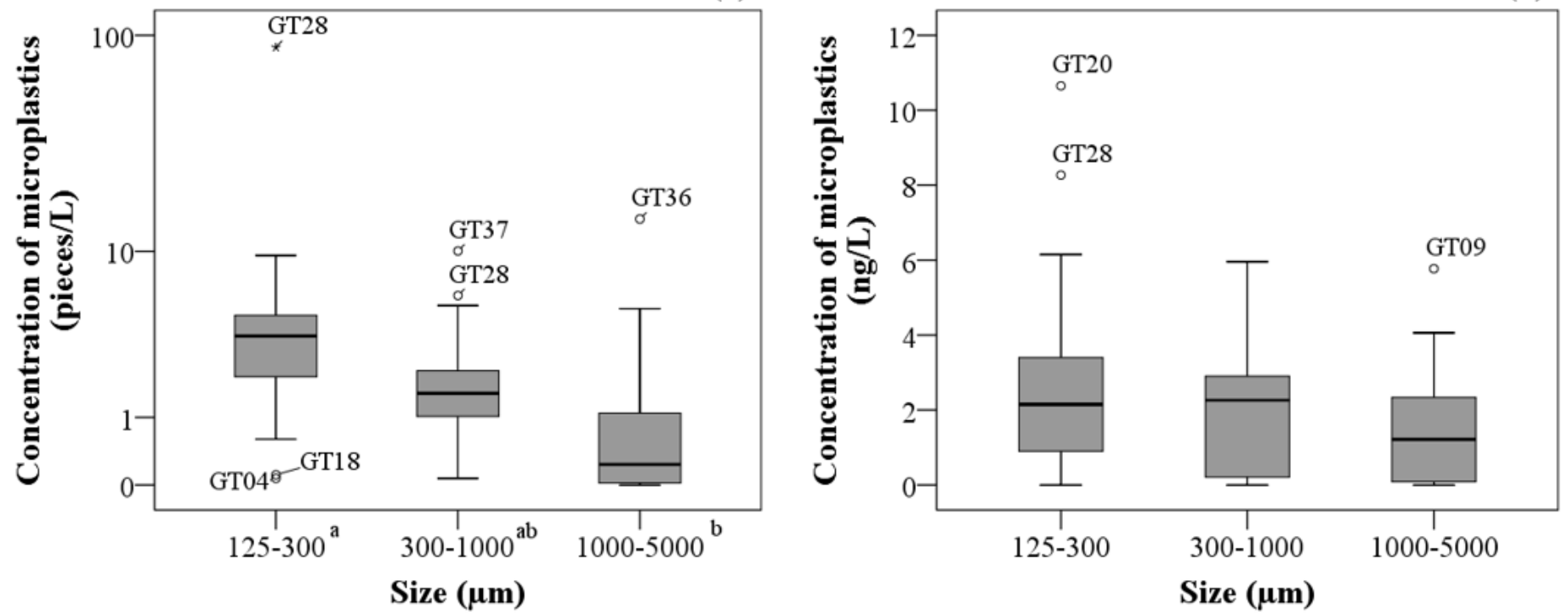

Figure 4

Variation in the concentration of microplastics sized 125-300, 300-1000, and 1000-5000 $\mu \mathrm{m}$ : (a) the concentration expressed as "pieces/L" and (b) the concentration expressed as " $n g / L$ " (a and b demonstrate statistical significance in terms of the concentration of microplastics of each size) 
(a) Total MPs $(125-5000 \mu \mathrm{m})$

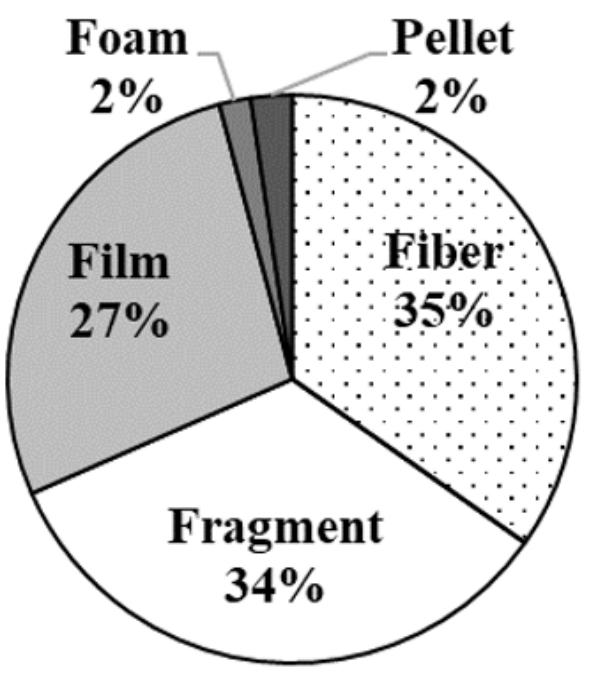

(c) $300-1000 \mu \mathrm{m}$

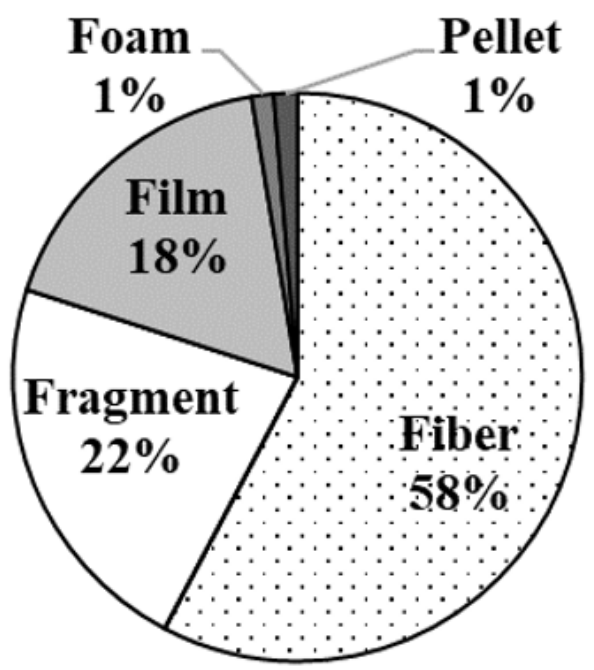

(b) $1000-5000 \mu \mathrm{m}$

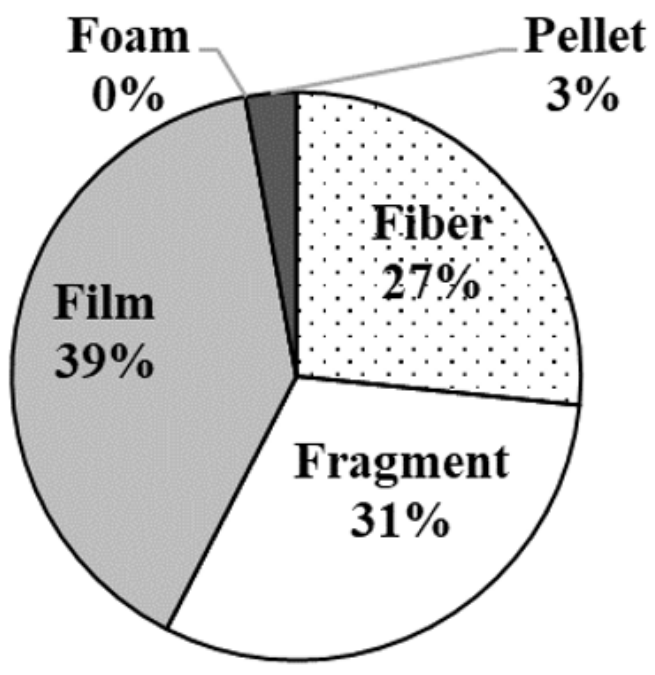

(d) $125-300 \mu \mathrm{m}$

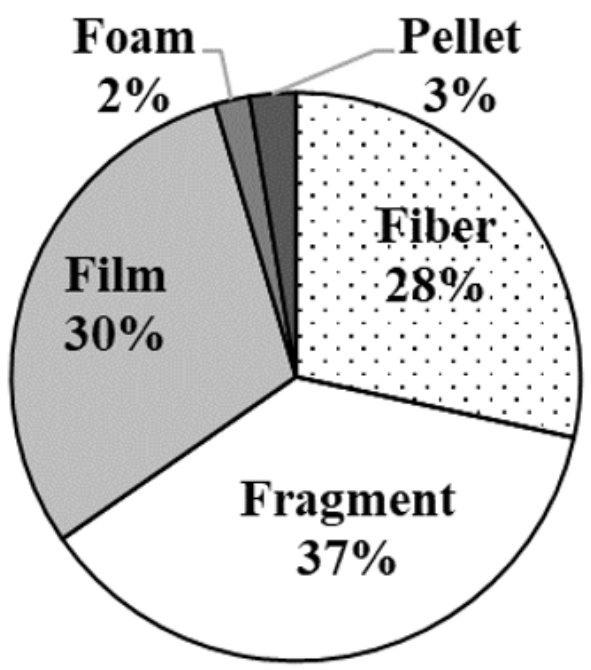

Figure 5

Shapes of microplastics in the surface seawater of the Inner Gulf of Thailand 
(a)

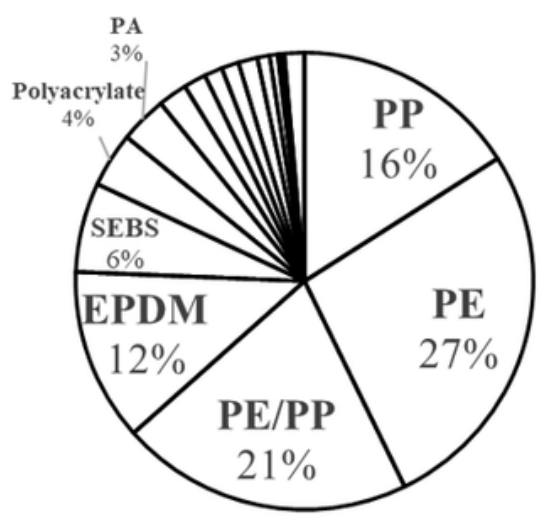

(c)

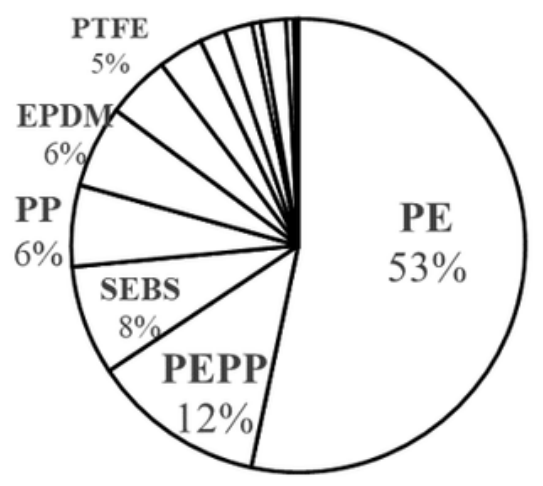

(e)

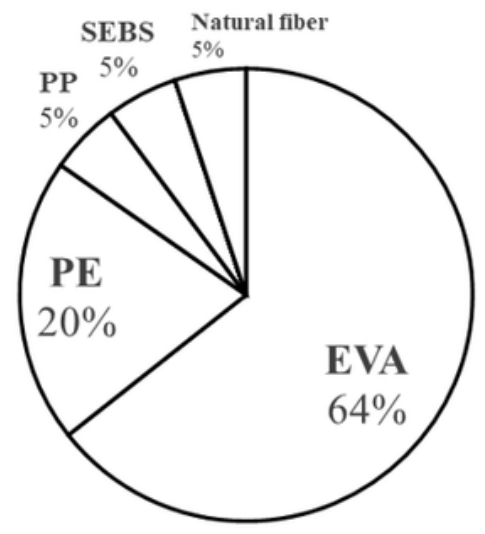

(b)

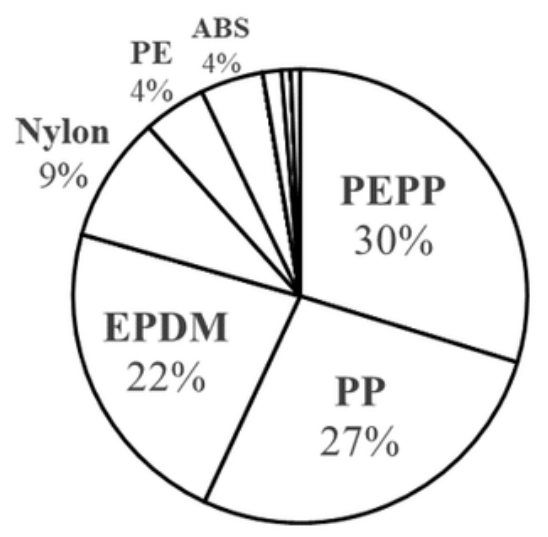

(d)

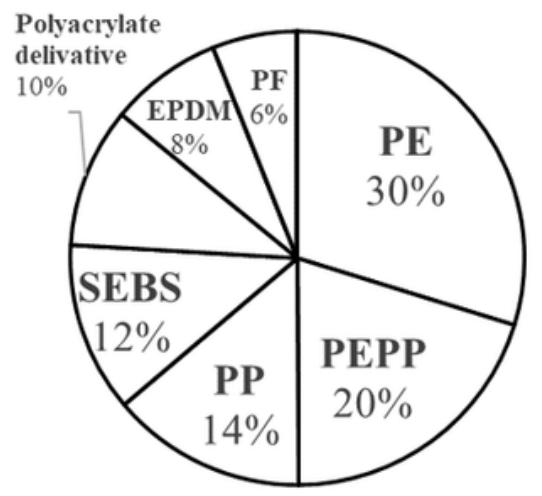

(f)

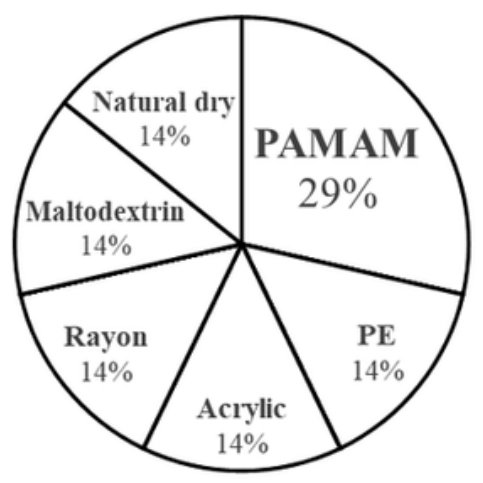

\section{Figure 6}

Polymer types in plastic samples: (a) total, (b) fiber, (c) film, (d) fragment, (e) foam, and (f) pellet 


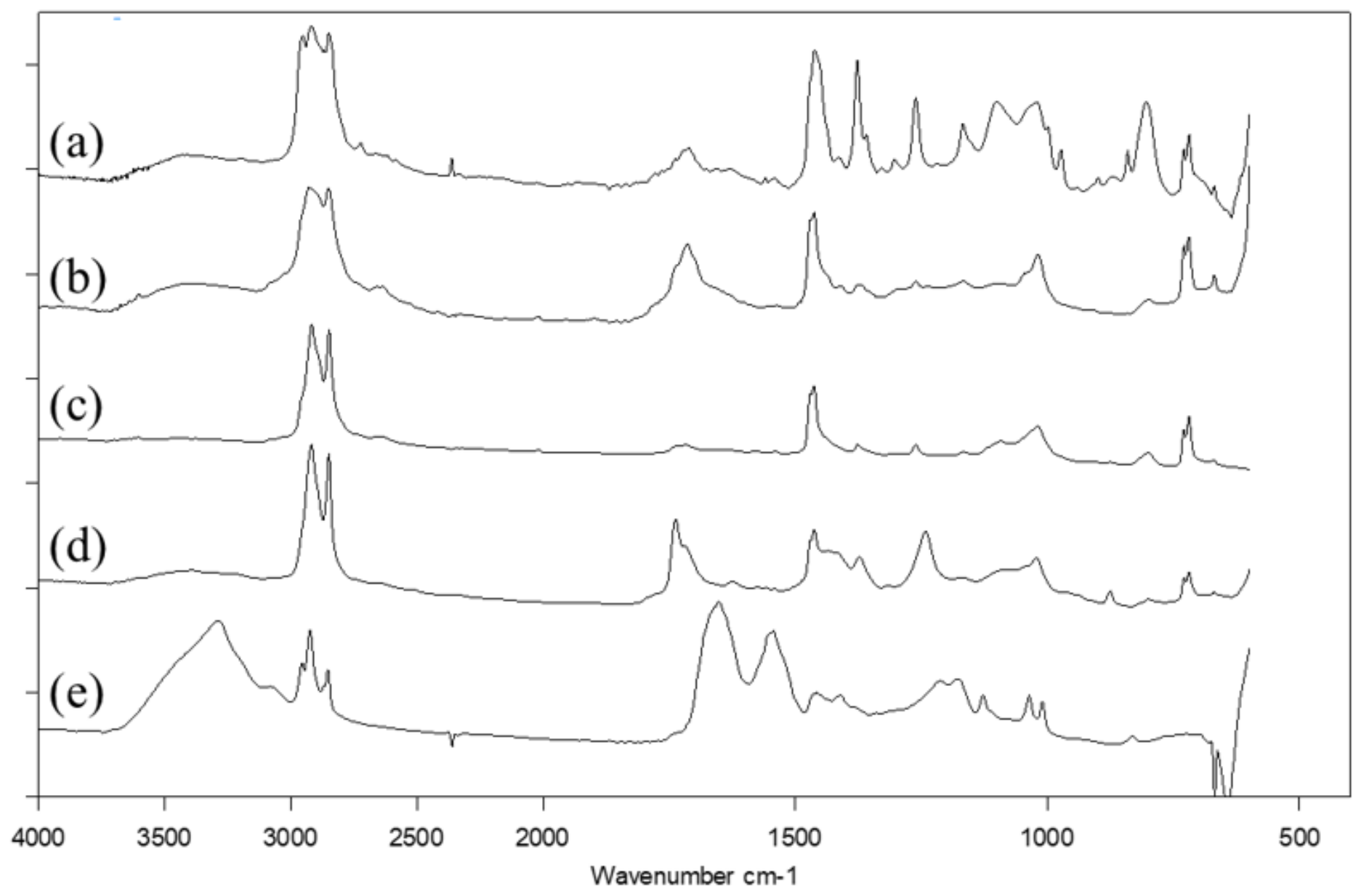

Figure 7

Fourier-transform infrared spectroscopy spectrum of microplastic samples: (a) polypropylene, (b) poly(ethylene:propylene), (c) polyethylene, (d) ethylene vinyl acetate, and (e) poly(amidoamine) 